\title{
RESUMOS DE DISSERTAÇÕES
}

1. Discente: David Pereira de Araújo.

Instituição: Programa de Pós-graduação em Direito Constitucional da Universidade Federal Fluminense (PPGDC-UFF).

Título da dissertação: "O CONTROLE DE CONVENCIONALIDADE NO NOVO CONSTITUCIONALISMO SUL-AMERICANO: UMA CHAVE PARA ENTRAR NA SALA DE MÁQUINAS?".

Banca examinadora: Professores Doutores Eduardo Manuel Val, Orientador e Presidente UFF, Guilherme Braga Peña de Moraes - UFF, Siddharta Ferreira Legale, Coorientador UFRJ e Raphael Carvalho de Vasconcelos - UERJ.

Data da defesa: 10/03/2020.

Resumo: A presente dissertação realiza uma revisão bibliográfica e jurisprudencial crítica de questões referentes a formação da ideia de Bloco de Constitucionalidade no Novo Constitucionalismo Sul-Americano, mais especificamente em países como Brasil, Colômbia e Venezuela. Nesse contexto, analisa de que forma a expansão da jurisdição interamericana tem contribuído para consolidação de direitos humanos, principalmente através da atuação da Comissão e da Corte Interamericana. Posteriormente, analisa a capacidade de diálogo entre as instâncias nacionais e internacionais através das chamadas "cláusulas de abertura" no corpo das novas constituições do Brasil e Colômbia. Em seguida, demonstra a importância que o poder judiciário exerce ao dar aplicação hermenêutica a favor, ou contrária, a ampliação dos canais de diálogo para além das fronteiras do Estado, atuando como uma espécie de mediador entre os demais poderes. Isso terá uma implicação direta na consolidação de valores fundamentais inerentes principalmente a minorias étnicas e sociais violentadas ao longo da história. Por fim, será demonstrado de que forma a ampliação dos canais de diálogo entre o Direito Constitucional e o Direito Internacional pode contribuir de maneira para a solução de controvérsias que envolvam graves violações de Direitos Humanos. O estudo parte da metáfora da "sala de máquinas" cunhada pelo professor Roberto Gargarella para representar a insuficiência da previsão normativa constitucional e da necessidade da intervenção de outros órgãos e poderes. O fim último, é atingir a ideia de acesso à justiça, cunhada pelo professor 
Antônio Augusto Trindade que não se basta em ter voz ativa internacional, mas em ter sua esfera de direitos inerentes a pessoa de fato amparada e protegida pelos órgãos competentes.

Palavras-chave: 1. Direito Constitucional. 2. Direitos Humanos. 3. Sistema Interamericano. 4. Democracia. 5. Produção intelectual.

2. Discente: Anderson Luís da Costa Nascimento.

Instituição: Programa de Pós-graduação em Direito Constitucional da Universidade Federal Fluminense (PPGDC-UFF).

Título da dissertação: "ENSINO JURÍDICO E (DE)COLONIALIDADE DO SABER: UMA ANÁLISE QUALI-QUANTITATIVA DOS PROGRAMAS DE PÓSGRADUAÇÕES EM DIREITO DO ESTADO DO RIO DE JANEIRO (2010-2020)".

Banca examinadora: Professores Doutores Enzo Bello, Orientador e Presidente - UFF, Gladstone Leonel da Silva Júnior - UFF, Ricardo Nery Falbo - UERJ e Otávio Luiz Rodrigues Júnior - USP.

Data da defesa: $31 / 03 / 2020$.

Resumo: Este trabalho tem por objeto o ensino jurídico nos Programas de Pós-Graduações Stricto Sensu em Direito (PPGDs) das seguintes universidades: UFF; UFRJ; UERJ; PUC/Rio; UNIRIO; UCP; UVA; UNESA; UCAM e FGV/Rio. Enfrentando a hegemonia eurocêntrica, transita entre eixos multidisciplinares, dentre os quais o pedagógico, o sociológico, o político, o econômico e, sobretudo, as questões epistêmicas. A metodologia é a mista (quali-quantitativa), aplicada às diversas técnicas de investigação, como a empírica, a documental, a bibliográfica e entrevistas semiestruturadas. A empiria foi formada por três dimensões: (a) o universo dos(as) docentes; (b) as fontes bibliográficas dos PPGDs; (c) e as dissertações e teses defendidas pelos(as) discentes, a fim de mapear aqueles cursos nas universidades eleitas. Entrelaçando o material empírico às entrevistas e às bases teóricas, a dissertação aporta na decolonialidade para que sejam reequilibradas as fontes bibliográficas nas disciplinas dos PPGDs, bem como sejam resgatadas as culturas oprimidas de todos os povos que foram sacrificados pela herança do processo colonial, em especial, a interculturalidade latino-americana. Para tanto, a pesquisa é militante, relexiva e ativa, em busca de uma transformação pedagógica concreta, rumo ao giro epistêmico e em defesa das epistemologias do sul. 
Palavras-chave: Estado; Educação em Direito; Direito Constitucional; América Latina; Pensamento descolonial.

3. Discente: Caio Cesar Moraes Grande Guerra.

Instituição: Programa de Pós-graduação em Direito Constitucional da Universidade Federal Fluminense (PPGDC-UFF).

Título da dissertação: “A CANDIDATURA AVULSA NO BRASIL: CONTROVÉRSIAS SOBRE A REPRESENTAÇÃO POLÍTICA NO BRASIL NA ERA DA DESCONFIANÇA”.

Banca examinadora: Professores Doutores Eduardo Manuel Val, Orientador e Presidente UFF, Guilherme Braga Peña de Moraes - UFF, Siddharta Ferreira Legale - UFRJ e Edson Medeiros Branco Luiz - UniFTC.

Data da defesa: 29/04/2020.

Resumo: No Brasil, novos movimentos sociais, em conjunto com plataformas midiáticas, vêm demandando mudanças no cenário político nacional e denunciando uma "crise de representatividade"; alegam que a "velha política" não consegue representar mais os anseios da sociedade, e exigem uma "nova política" que encarne uma nova voz para os novos tempos. Mas será que há de fato uma "nova política" dentro do atual cenário brasileiro? Tal pergunta, aparentemente de fácil resposta, nos obriga a fazer uma análise de representatividade política em diversos níveis, ou seja, em camadas, de forma minuciosa para que não haja equívocos no que se refere a problemática trazida. Assim cabe observar que "a crise" está constituída por várias crises (econômicas, sociais, culturais dentre outras) em nome da política de austeridade do Estado brasileiro, se propõe sérios recortes aos direitos sociais como fica evidente nas recentes reformas trabalhista e da previdência. Diante disso, diante de um emaranhado teórico, ressurge o debate sobre as candidaturas independentes, com isso, o presente trabalho se apresenta como "A Candidatura Avulsa no Brasil: Controvérsias sobre a representação política no Brasil na era da desconfiança”, ou seja, de que forma a candidatura avulsa (conhecida como independente) se apresenta no cenário político/constitucional brasileiro? Para isso, far-se-á uso do método hipotético dedutivo, no qual delimitou-se um fato-problema, qual seja, a análise da descontinuidade democrática brasileira em razão da manutenção de partidos políticos como única forma de elegibilidade, para que então se procedessem à hipóteses e, inclusive, elaboração de possíveis consequências ao cenário distinto que se propõe: a candidatura avulsa; pretendeu-se a 
experimentação com a análise dos casos que versão sobre a possibilidade deste novo meio de eleição a ser testado. O uso de embasamento teórico, tal como da análise jurisprudencial comparada à legislativa também foram de grande valia para o presente trabalho. Cumpre esclarecer que a análise jurisprudencial será feita a partir da metodologia proposta por Luly Fischer, da qual será disposta em momento oportuno. Além disso, o referencial teórico é de Norberto Bobbio, Pierre Rosanvallon e Carole Pateman.

Palavras-chave: Direitos Humanos; Direito Constitucional; Candidaturas Avulsas.

4. Discente: Bruno Joviniano de Santana Silva.

Instituição: Programa de Pós-graduação em Direito Constitucional da Universidade Federal Fluminense (PPGDC-UFF).

\section{Título da dissertação: "COMPLEXO PRISIONAL DE PEDRINHAS: VULNERABILIDADE E SELETIVIDADE".}

Banca examinadora: Professores Doutores Taiguara Líbano Soares e Souza, Orientador e Presidente - UFF, Roberta Duboc Pedrinha - UFF, André Luiz Nicolitt - UFF, Antônio Eduardo Ramires Santoro - UFRJ e Salo de Carvalho - UFRJ.

Data da defesa: $13 / 05 / 2020$.

Resumo: O presente trabalho busca analisar criticamente o cárcere pátrio, máxime maranhense, pelas lentes do Complexo Prisional de Pedrinhas. Nesse passo, a presente investigação considera a pessoa privada de liberdade, sob o viés da vulnerabilidade, em um panorama de violação continuada e sistemática aos seus direitos fundamentais, influenciado pelos influxos do paradigma da modernidade em interação com outros elementos para a conformação de um sistema penitenciário seletivo, que opera sob a lógica excludente, de hostilização e despersonalização "do outro" e de contenção social, perceptível em escala nacional e regional (maranhense). Para tanto, valeu-se do marco teórico da Criminologia Crítica, recorrendo-se ao enfoque cartográfico e interdisciplinar, de modo a compreender a realidade carcerária pátria e regionalizada (maranhense) eivada de indignidade estrutural, em um contexto de seletividade carcerária, no bojo de uma racionalidade prisional que aponta para a falência do "modelo ressocializador prisional" e o soerguimento de uma lógica de neutralização seletiva que embaraça a efetividade do princípio da dignidade da pessoa humana e toda a coluna protetiva de direitos fundamentais no âmbito carcerário. 
Palavras-chave: vulnerabilidade; seletividade; pessoa privada de liberdade; cárcere; despersonalização.

5. Discente: Juliana Patrício da Paixão.

Instituição: Programa de Pós-graduação em Direito Constitucional da Universidade Federal Fluminense (PPGDC-UFF).

Título da dissertação: "ESTADO DE COISAS INCONSTITUCIONAL: DA TEORIA À CONSOLIDAÇÃO DO SISTEMA DE PENSAMENTO NO BRASIL”.

Banca examinadora: Professores Doutores Guilherme Braga Peña de Moraes, Orientador e Presidente - UFF, Eduardo Manuel Val - UFF, Gustavo Sampaio Telles Ferreira - UFF e Siddharta Legale Ferreira - UFRJ.

Data da defesa: $14 / 05 / 2020$.

Resumo: O tema do trabalho delimita-se no estudo acerca da reação dos três Poderes perante a teoria do estado de coisas inconstitucional (ECI) reconhecida na ADPF 347/DF, que trata da seletividade da efetividade dos direitos fundamentais para apenas algumas camadas da sociedade. O intuito é realizar a análise das condições socioeconômicas e políticas para apoio e avanço do ECI nos EUA e cotejar com a ausência desse substrato político e socioeconômico na atuação ambivalente das instituições brasileiras a partir de setembro de 2015, data da liminar proferida na ADPF 347/DF.

Palavras-chave: Estado de Coisas Inconstitucional; Jurisdição constitucional; Ativismo judicial; Sentença estrutural.

6. Discente: Rebecca Féo de Oliveira.

Instituição: Programa de Pós-graduação em Direito Constitucional da Universidade Federal Fluminense (PPGDC-UFF).

Título da dissertação: “APLICAÇÃO DOS PRINCÍPIOS CONSTITUCIONAIS PENAIS NO DIREITO ADMINISTRATIVO SANCIONADOR - ANÁLISE DOS PROCESSOS DA ANP”.

Banca examinadora: Professores Doutores Taiguara Líbano Soares e Souza, Orientador e Presidente - UFF, Roberta Duboc Pedrinha - UFF, José Vicente Santos de Mendonça UERJ e Rafael Carvalho Rezende de Oliveira - IBMEC. 
Data da defesa: $20 / 05 / 2020$.

Resumo: Este trabalho avalia da aplicação dos princípios previstos no artigo $5^{\mathbf{o}}$ da Constituição de 1988 que são identificados diretamente com o Direito Penal: legalidade, retroatividade benéfica, intranscendência da pena e individualização da pena, ainda que com matizes, no Direito Administrativo Sancionador. A aplicação é pertinente para preservar os direitos fundamentais dos submetidos à ação punitiva do Estado, mesmo que pessoas jurídicas. Isso porque as infrações administrativas têm aumentado, sem que, contudo, haja um regramento próprio acerca da matéria no Brasil. Os processos administrativos sancionadores julgados pela Diretoria da Agência Nacional do Petróleo, Gás Natural e Biocombustíveis ANP em última instância administrativa no primeiro semestre do ano de 2019 serviram de base para a análise.

Palavras-chave: Direito Administrativo Sancionador; legalidade; retroatividade benéfica; ANP.

7. Discente: Tatiana Ferreira Lotfi.

Instituição: Programa de Pós-graduação em Direito Constitucional da Universidade Federal Fluminense (PPGDC-UFF).

Título da dissertação: “A VIOLÊNCIA DE GÊNERO NA INTERSECÇÃO DAS CATEGORIAS 'MULHER' E 'REFUGIADA'”.

Banca examinadora: Professores Doutores Clarissa Maria Beatriz Brandão de Carvalho Kowarski, Orientadora e Presidente - UFF, Eduardo Manuel Val - UFF e Denise Mercedes Nuñes Nascimento Lopes Salles - UCP/RJ.

Data da defesa: 08/06/2020.

Resumo: O conceito universal de refugiado previsto na Convenção de 1951 e no Protocolo de 1967 não alcança a perseguição fundamentada no gênero. A Lei 9.474/97 adotou uma definição ampliada, que reconhece o refúgio em casos de grave e generalizada violação a direitos humanos. Apesar dessa ampliação, o conceito brasileiro de refúgio também é insensível à perspectiva de gênero. Vozes na academia passaram a se insurgir contra a neutralidade de gênero existente não apenas na definição universal de refugiado como em grande parte das pesquisas sobre migração. Organismos internacionais como o ACNUR e o Comitê CEDAW expediram documentos denunciando a maior vulnerabilidade das refugiadas à violência de gênero e orientando profissionais diretamente encarregados da análise de 
elegibilidade a reconhecer o refúgio de mulheres com base no pertencimento a grupo social quando a perseguição se exteriorizar através da violência de gênero. Convencidas da importância de incorporar o gênero às pesquisas migratórias, Grieco e Boyd (2003) desenvolveram um método que segmenta a atividade migratória em três etapas - prémigração, cruzamento de fronteira e pós-migração - e oferece uma estrutura de análise para identificar questões de gênero em cada uma destas etapas. Em nossa pesquisa, aplicaremos o método de Grieco e Boyd para identificar a violência de gênero na etapa pré-migratória, como motivação para a fuga, nos depoimentos das participantes do Projeto "Vidas Refugiadas" e analisaremos se a violência relatada por estas mulheres serviria de base para o reconhecimento do refúgio no Brasil.

Palavras-chave: refúgio de mulheres; violência de gênero; grupo social específico; projeto "Vidas Refugiadas". 